\title{
Inter-professional education/learning across social work education provision in Scotland.
}

\author{
BOLGER, J.
}

2020

This is an Accepted Manuscript of an article published by Taylor \& Francis Group in Journal of Further and Higher Education on 04/03/2019, available online:

http://www.tandfonline.com/10.1080/0309877x.2019.1576861. 


\section{Inter-professional Education/ Learning in Scottish HEIs: I mplications for}

\section{Social Work Education Provision}

Janine Bolger, Head of Social Work, School of Applied Social Studies, Robert Gordon University, Aberdeen, Scotland

\section{Abstract:}

This research study was undertaken to map out Inter Professional Education, (also known as Inter Professional Learning or IPL), provision across Higher Education Institutions delivering qualifying social work programmes in Scotland. Its purpose was also to identify the strengths and weaknesses of approaches to Inter Professional Education (IPE) and ascertain the views of social services workers about the direct impact of such programmes on practice.

On-line surveys were completed by social work students across Scottish universities, representatives from those delivering inter-profession education/learning (IPE/IPL) and employers of newly qualified social workers.

Students and employers were generally satisfied with the type and quality of IPE/IPL offered which was thought to be well integrated through qualifying programmes. Provision was clearly articulated and implanted within strategy and course documents.

This research found that IPE/IPL undertaken by social workers in training in Scotland was impacting positively on service delivery. However, it also found that institutional organisation continued to compound difficulties in creating relevant and useful IPE/IPL activity. 


\section{Key words:}

Inter-professional education; inter-professional learning; social work education; collaborative professional practice; evidence-based practice.

\section{I ntroduction}

From the 1970's onwards a knowledge based model of Inter-professional Education/Learning (IPE/IPL) was developed. Content focussed on curricula thought to be applicable both to education and to practice in and between each of the professions taking part. It incorporated commonalities of language, knowledge and ideas which underpinned collaborative practice (Barr 1998) to the detriment of differences. An appreciation of the distinctive qualities of different professions resulted in the introduction of comparative learning. This fostered a better understanding of respective roles and responsibilities and with those a greater opportunity to develop mutual trust and to dispel stereotypes, resulting in strengthening of relationships and improvement in collaborative practice. Attempts to evaluate such claims have been inconclusive (Barr and Shaw 1995). Even where inter-professional education appeared to bring about a change in attitude, behavioural changes were not necessarily inevitable and, where they did occur, were not always long lasting.

Until 2006, research and evaluation into IPE/IPL provision within social work education has received little attention, perhaps because social work students and educators have frequently been minority participants (Barr and Sharland 2012). That in itself is strange, not least because the Standards in Social Work Education (Scotland), the Professional Capability Framework (the rest of the UK) 
and the Social Work Subject Benchmark statement for social work education acknowledge that social work practice takes place in inter agency contexts and that social workers are required to work collaboratively with others towards interdisciplinary and cross-disciplinary objectives.

In practice, findings from a wide range of inquiry reports and significant case reviews have repeatedly reinforced the argument for effective partnership working. The dangers of working in isolation from other agencies along with poor information sharing, failings in communication and inadequate multi-agency working arrangements have been linked to serious consequences. Significant Case reviews such as that relating to the death of Brandon Muir in 2008 identify a need for multi-agency ownership and leadership and raise matters concerning the evaluation and sharing of information (Hawthorn and Wilson 2009). However, we should be cautious not to view inter-professional working as the panacea to all social problems.

“Collaboration and inter-professional, interdisciplinary or multi-professional working have been sported almost as a talisman which, once touched, will rid the world of social work, health care and other human services of the narrow, tribal and often damaging practices that are held responsible for social tragedies" (Quinney and Hafford-Letchfield 2012. pix).

The Centre for Advancement of Inter Professional Education (CAIPE) has long argued that collaboration is taught more effectively with students from more than one profession taught together. As demands have grown for both evidence based practice and evidence based education, pressure has increased to subject IPE/IPL programmes to more rigorous evaluation. It is generally acknowledged that there are signs of productive and effective IPE/IPL within social work 
education in the UK but that its claims for success have yet to be established. Practical, resource (timetabling and other curriculum requirements) and cultural challenges (resistance to the crossing or blurring of traditional disciplinary boundaries) have been seen as significant barriers in the embedding of IPE/IPL opportunities into professional training (Barr and Sharland 2012).

There is evidence to support the value and integrity of IPE/IPL. Learning in practice, experiential classroom based learning and opportunities to build formal and informal relationships across professional boundaries have been evaluated favourably over time (Anderson and Lennox 2009; J oseph, et al 2015). Robust evidence relating to the more ambitious outcomes of IPE/IPL, such as sustained improvement in collaborative practice, better outcomes for service users and improvement in inter-professional services is most lacking.

\section{Inter Professional Education/ Learning in Social Work Education in Scotland}

This study into Inter Professional Education/Learning (IPE/IPL) was requested by the Scottish Social Services Council (SSSC), the regulatory body for social work in Scotland, as part of phase two of the Review of Social Work Education in 2015-16. The aim was to explore what is currently addressed on social work courses in Scotland and how it is delivered. This consisted of a literature review and a questionnaire survey. Ethical approval was gained from the School's Ethics Committee and participation in the project was voluntary. Anonymity was guaranteed. All participants were provided with information relating to protection of data. 
The intent was to capture the views of employers, students and from representatives from Higher Education Institutes (HEIs) in relation to the efficacy and challenges of current approaches. A view as to what might strengthen the quantitative and qualitative experience of students in relation to

IPE was formed. A process of evaluation research was adopted. A mixed method design was employed via an online questionnaire to allow for information to be gathered from students studying with different social work education providers across Scotland.

Final year social work students on undergraduate and postgraduate programmes (full-time and distance learning) from all eight providers of social work education in Scotland were invited by the researcher, through their own institutions, to complete an on-line questionnaire. Out of a total population of approximately 459 final year (undergraduate and postgraduate) students, there were 43 responses (approximately a 10\% response rate). An academic lead for IPE/IPL from each HEI was sent an on-line questionnaire and six $(n=8)$ Scottish HEIs responded. 24 employers representing Local Authorities $(n=9)$, third sector $(n=3)$ and private organisations $(n=2)$ who employed social work graduates from Scottish HEls within the previous year participated.

Search Methods

A literature search was conducted in January 2016 using EBSCO, Web of Science, Science Direct and Google Scholar electronic archives. Manual searches were conducted of The British J ournal of Social Work and the most common Social Care periodicals, as well as via the Institute for Research and Innovation in Social Services (IRISS), Social Care Institute for Excellence (SCIE), The 
Centre for Advancement of Advancement in Inter Professional Education (CAIPE) and Social Services Knowledge Scotland (SSKS) websites.

Primary search terms were 'Inter professional education', 'Inter professional learning' OR 'IPE’/'IPL’ OR ‘Interdisciplinary education’. Secondary search terms included 'student' AND 'health education' AND 'service users' AND 'social work education'. The review focussed on studies: of the development or delivery of IPE/IPL; that explore the practice of IPE/IPL; that explore the perceptions of students/employers or HEIs in relation to IPE. As the study's focus was around the provision of IPE/IPL within qualifying social work programmes in Scotland, only studies conducted in the United Kingdom were considered to allow for more suitable comparisons to be made. Given the limited amount of research into inter professional education in the UK, the exclusion criteria were limited to the exclusion of studies that related to IPE/IPL which did not involve social work students or focussed on preparation for only one specific area of practice (e.g. domestic violence). A time limit of research conducted within the last twelve years was set.

Research Literature

IPE/IPL into the Social Work Curricula

Firstly, drawing on a wide range of sources in their review of "Inter Professional education for qualifying social work", Sharland and Taylor (2007) suggest that there is a lack of social work specific research focus in IPE/IPL research. This has been the experience also in conducting this research as can be seen by the 
content of this section. Sharland and Taylor (2007) found that IPE/IPL programmes predominantly involved collaboration only between the social work, nursing and allied health professions. Additionally, the majority of courses appeared to introduce IPE/IPL only in the latter stages of study.

Low and Barr (2008) considered how social work education providers in the UK deliver IPE/IPL training. The study of $13 \mathrm{HEIs}(n=72)$ gathered views from students, tutors and service users although the number of students that participated was small. It focussed primarily on practical learning of skills such as team working. Information on delivery and assessment was also examined. Findings identified that the relationship between social worker and service user provided the foundation for good collaborative multi-professional partnerships. It was recognised that knowledge and skill development around interprofessional working was provided through education in the classroom and in practice and, as such, a number of logistical challenges were evident.

Barr, Helme and D'Avray's (2011) progress report provided an in-depth view of IPE/IPL from 1997. Reference to available literature and to materials and research published outwith the usual commercial or academic publishing and distribution channels (grey material) augmented findings from HEA and CAIPE records, a survey and the use of case studies. The authors chronicle the rise of IPE/IPL and the pressures faced by professionals prior to its introduction, as well as the increasing demand for more overlap between professions. Claims that professional institutions were impeding the advance of IPE/IPL provision were generally discredited. The absence of national structures to bring together education and professional institutions, government departments and local government associations, the Higher Education Academy (HEA) and CAIPE to 
review progress, identify and act on related policy issues and support developments in delivery and practice was highlighted. The establishment of local partnerships appeared to sustain IPE while changing priorities, perceptions and circumstances in HEls impacted on provision.

In a later study, Barr et al (2014) examined prequalifying IPE/IPL between 1997 and 2013 in institutions delivering education and training to health and social care professions across the UK. Their review drew on three sources: available literature, an online survey and the use of reflective accounts with follow-up interviews with health and social care professionals. The study highlighted that at least two thirds of universities $(n=127)$ with qualifying courses in health and social care included IPE/IPL. Their findings suggested that IPE/IPL was becoming more integrated into professional programmes with discrete IPE/IPL modules becoming less evident. Learning methods were interactive with a focus on development of mutual respect and understanding through consideration of professional similarities and differences. Face-to-face learning was augmented by e-learning and IPE/IPL elements within practice learning were strengthened. The role of the IPE/IPL Co-ordinator was found to be crucial and institutional endorsement of programmes was critical. Unilateral changes in IPE/IPL provision across different professional programmes disrupted activity in others and internal and external evaluation of programmes placed differing value on the merit of IPE provision across professions. The synchronisation of interprofessional learning and assessment in practice learning was found to be particularly problematic. 
The discussion paper published by Stevenson et al (2012) examines IPE/IPL delivery at undergraduate level. With a focus on the introduction of IPE/IPL at Glasgow Caledonian University in 2004 it highlights the implementation of a web based peer-assessment tool for IPE/IPL. The paper identifies how this method differentiates between students who are working effectively in inter-professional teams and those who are not.

The Impact of IPE/IPL

Few studies have assessed the effects of the impact of IPE/IPL. One exception is Anderson and Lennox (2009) who undertook a 10 year longitudinal study in an under privileged area of Leicester, where one of the first multi-disciplinary centres was developed in 1995, in an attempt to more adequately meet the community's needs via one health care centre. They emphasised the need to integrate education research into the development and delivery of IPE/IPL and to engage with practitioners who recognise the student's contribution to team working by placing users of services at the centre of the learning experience and through developing local working partnerships (HEIs, health and social care agencies and the third sector). The Leicester Model was recognised as one of the few examples of sustainable inter-professional learning within practice settings. Students were able to reconcile theory to practice whilst preparing for the realities of practice. This model has since been adopted nationally and internationally in Belgium and Japan.

Foster and Macleod Clark (2015) address the shortage of empirical evidence around the positive impact of IPE/IPL. This study on the stereotypical beliefs towards colleagues from other disciplines, of undergraduate health and social 
care students from the University of Southampton compared the views of 580 students from 10 health and social care professional groups at the beginning and end of their studies. The findings were compared to those from 672 students not exposed to IPE/IPL. Baseline patterns of stereotypical beliefs were similar for both intervention and comparison groups but, after completion of undergraduate studies a greater decrease in those beliefs were found amongst the group that had experienced IPE/IPL modules.

Through their review of twenty studies undertaken between 1996 and 2003, Gillies et al (2004) identified key themes linked to inter-professional education/learning. A wide range of benefits in relation to the outcomes of existing IPE/IPL programmes were discovered, e.g. the acquisition of increased knowledge of roles and responsibilities, greater respect between professions, enhanced confidence in collaborative practice and diminished suspicion between professions. Barriers to effective inter-professional practice were considered to be financial, cultural, organisational and professional and believed to be linked to perceptions of status differentials. Other key findings were around the positive level at which IPE pre and post qualification was received and the innovative learning opportunities employed by HEIs.

\section{Summary of Findings}

Responses were received from final year students studying at both undergraduate $(n=300)$ and post graduate levels $(n=168)$ and studying parttime/distance learning ( $19 \%$ of respondents) and full-time ( $81 \%)$. Response rates across HEls varied from $x-19 \%$ of postgraduates to $y-81 \%$ of undergraduates. 
Findings in relation to the key questions informing inquiry suggest the following:

The nature and extent of inter-professional learning in social work courses:

The study identified that IPE/IPL is delivered in a range of different ways across Scottish HEIs. Common methods of engaging students in IPE/IPL appears to be through shared group activity with students from other professions, as part of both shared assessed modules and via discrete social work focussed modules, in practice learning (placements) and at dedicated IPE/IPL events.

The frequency that students engage with IPE/IPL and the location within different programmes when students are exposed to such activity also varied. The following examples are highlighted in Figures 1-5 below:

- Group IPE activity took place on a weekly, monthly and yearly basis. Group IPE/IPL activity occurred during all but the final stage of qualifying programmes.

- Shared assessed IPE/IPL modules were delivered on a regular basis through all stages of programmes.

- Discrete assessed Social Work specific modules involving IPE/IPL are delivered regularly and across all stages of programmes.

\section{Group Activity}

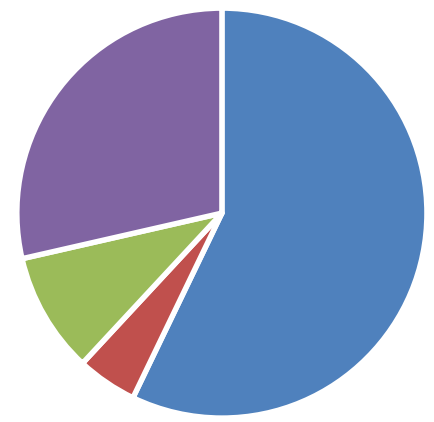

- Yearly - Monthly - Weekly - Block 
Figure 1. Group Activity - frequency.

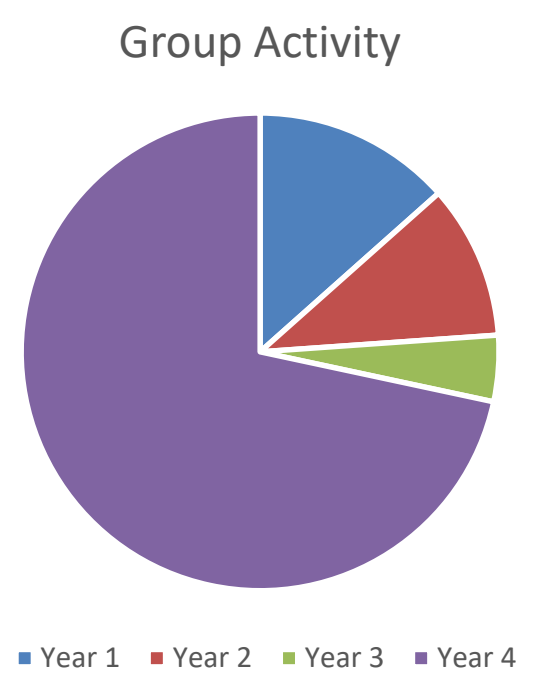

Figure 2. Group Activity - occurrence.

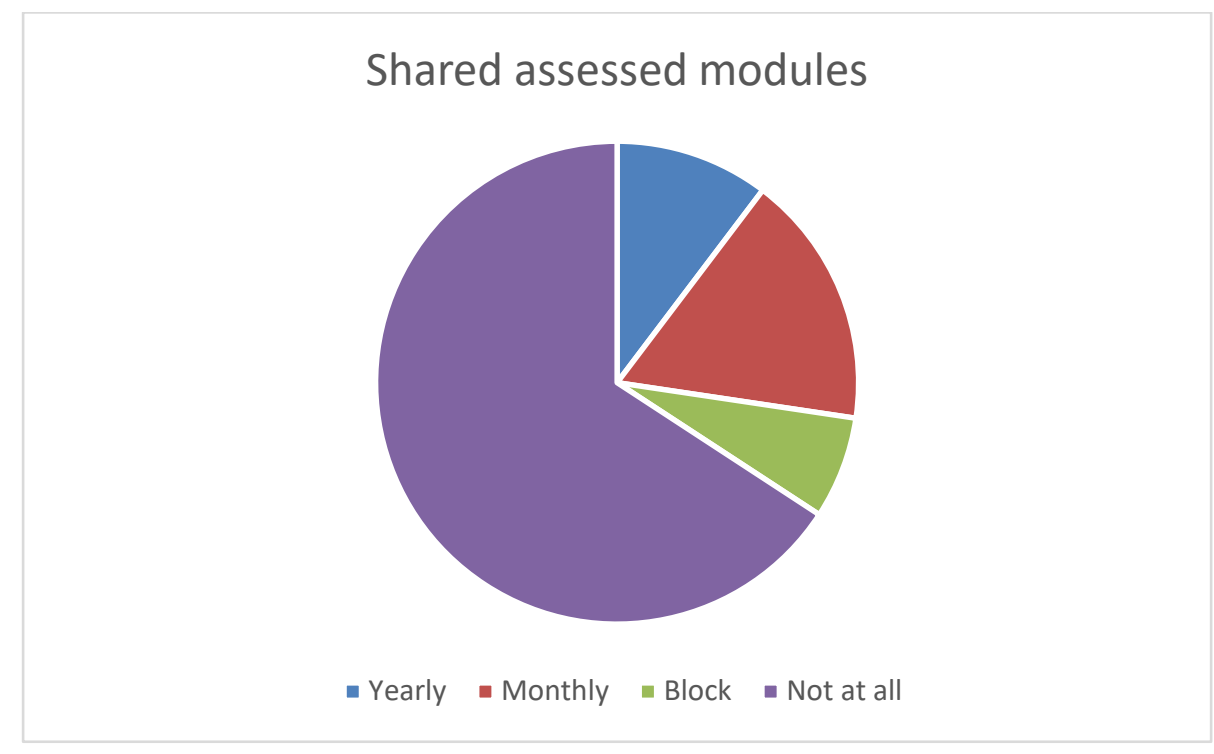

Figure 3. Shared assessed modules frequency. 
Shared assessed modules

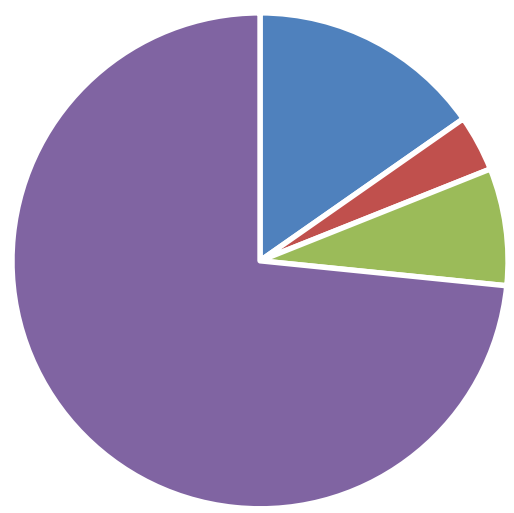

- Year 1 - Year 2 - Year 3 - Year 4

Figure 4. Shared assessed modules - occurrence.

Discrete assessed modules

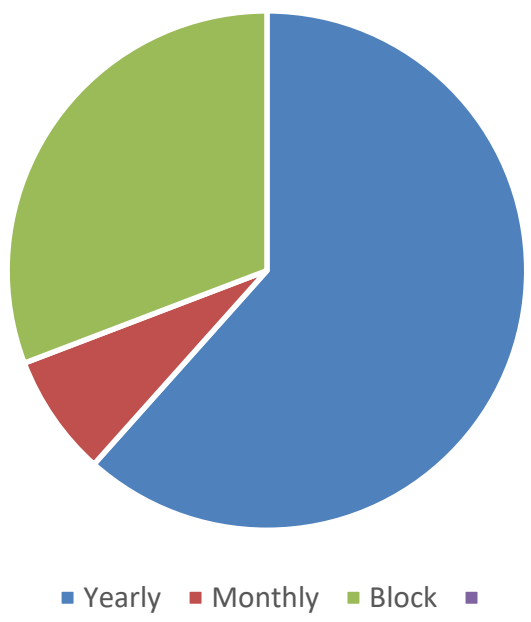

Figure 5. Discrete assessed module - occurrence.

Content of IPE/IPL Programmes

Students reported that IPE/IPL programmes considered:

- Common and discrete professional roles

- Common and discrete professional values

- Common and discrete professional skills 
- Common and discrete professional knowledge

Students stated that the most important and useful aspects of IPE/IPL for them was around gaining knowledge, learning about other professional groups, their values, roles and the inherent limitations.

IPE/IPL was delivered to Social Work students along with students from a range of professions which included nursing, midwifery, education, occupational therapy, physiotherapy, pharmacy, medicine, dieticians, police, sports science. Interaction was largely direct (face-to-face) with some indirect (online activity).

Changes brought about through IPE/IPL

Kirkpatrick's (1967) model of classification of educational outcomes was partially adopted in order to consider the students' reaction to the educational experience, behaviour change as a result of the learning and outcomes (Carpenter 2011).

Students acknowledged improvements in collaborative practice, changes in attitudes towards other professions, overall learning and in the improvement of their skills. When looking at behavioural change as a result of IPE/IPL, students identified changes in their:

- awareness of different professional roles

- understanding of their role as social worker

- understanding of how different professional roles overlap

- understanding of the limitations of different professional roles

- understanding of activities which fall between specific professional roles 
- ability to challenge stereotypical professional roles

- skills in inter-professional teamwork

- ability to recognise and adopt good models for collaborative practice

- preparation for professional practice in inter-disciplinary contexts

Five of the eight HEIs who participated delivered IPE/IPL opportunities across all their social work qualifying programmes.

Perceived Strengths in IPE/IPL provision

The majority of the HEIs explicitly articulated IPE/IPL provision in their School Strategy and in their Course Documentation with just under half of them also making explicit reference within their Teaching and Learning Strategy.

Awareness of the nature of IPE/IPL activity was high with the majority of employers being aware of IPE/IPL programmes in their local universities.

Employers perceived graduates' understanding as 'good' or better with regard to:

- their own professional role and skills ( $48 \%$ good, $44.8 \%$ very good)

- the roles and skills of other professionals ( $62.1 \%$ good, $17 \%$ very good)

- the knowledge base and values of other professionals $(62.1 \%$ good, $10.3 \%$ very good)

- the ability to develop and maintain relationships with other professional ( $55.2 \%$ good, $37.9 \%$ very good)

- the ability to work collaboratively with other professionals (51.7\% good, $44.8 \%$ very good) 
Notably $27.7 \%$ of employers felt that graduates had poor understanding of the knowledge base and values of other professionals while $20.7 \%$ thought that there was poor understanding in relation to the roles and skills of other professionals.

Impact of IPE/IPL

Most employers (66\%) considered that there was a positive impact on practice and service delivery as a result of IPE/IPL. The other employers were unable to make a comment on the impact of IPE/IPL.

The majority of students, universities and employers in this study recognised that IPE/IPL provision helps equip social workers in training to develop awareness of different professional roles; achieve a clearer understanding of their role as social worker; gain a greater understanding of how different professional roles overlap; acquire an understanding of the limitations of different professional roles; understand activities which fall between specific professional roles; gain the ability to challenge stereotypical professional roles; develop skills in inter-professional teamwork; recognise and adopt good models for collaborative practice and, ultimately, be better prepared for professional practice in inter-disciplinary contexts

Challenges to the Provision of Effective Inter-professional Education/Learning Only $50 \%$ of HEI representatives believed that IPE/IPL activity was positively received by students. 
Some employers felt that the operation of different models for providing social care presented the greatest challenge for the future of IPE/IPL provision along with different professional priorities within the workplace. Many employers surveyed believed that it was the hierarchies amongst the different professional groups that brought the greatest challenges for inter professional education/learning while others suggested that the reality of assisting graduates to understand the pressures faced by different professionals and addressing poor communication between different professionals were the greatest challenges.

\section{Discussion and Conclusion}

Conclusions drawn from student feedback in this study must be considered with some caution given the small sample size and the participation of students from only five of the seven HEls who provide social work education in Scotland. The employers who responded were self-selecting.

IPE/IPL within social work education across Scottish HEls is delivered in an integrated manner through regular shared group activity, as part of shared assessed modules and in practice learning. To augment such practice some HEI s run dedicated IPE/IPL events where students from across professions engage in a shared face-to-face activity. Face-to-face delivery is complemented

with e-learning in line with recommendations from the Review of Interprofessional Education in the UK (Barr et al. 2014). There is evidence that IPE/IPL also continues to be delivered via discrete social work modules. The focus of IPE/IPL appears to be largely around the development of knowledge, skills and values and on understanding and development of professional identity and roles across professionals (Chambers et al. 2013). The findings indicate 
satisfaction from students and employers in terms of the value of collaborative learning, the focus of IPE/IPL, the timings, organisation and usefulness of IPE/IPL. Students appear to see themselves as active participants within IPE/IPL preparing themselves for working within integrated service contexts.

Issues relating to institutional organisation continue to present some challenges to how and when IPE/IPL is delivered (Barr et al. 2014; Sharland and Taylor 2007). HEls should be supported in aligning courses to optimise interprofessional learning with reference to staffing, timetabling and placement patterns. Furthermore, HEI s should continue to regularly review their IPE/IPL provision to ensure fitness for purpose and to develop it accordingly. In order to support the continued provision and integration of such activity it would seem appropriate to avoid the imposition of regulation in terms of standardising practice and policy. Any attempt to impose standardisation would likely exacerbate any organisational challenges faced.

Caution must be exercised, however, in assuming that bringing a group from different professional backgrounds together will automatically change knowledge, attitudes, values and skills for the better (Gillies et al. 2004). Consideration, therefore, must be given to the nature of the provision. IPE/IPL provision appears to be clearly articulated and implanted within relevant strategies and course documentation in line with recommendations from the latest review (Barr et al. 2014). This, perhaps, emphasises the accepted relevance for practice and the importance with which IPE/IPL is viewed. In line with aspirations for quality improvement of services, employers did suggest that IPE/IPL programmes prepared graduates well in relation to understanding the knowledge base, professional roles and skills of themselves and other 
professionals. Feedback suggested that many employers believe graduates have a good level of ability to develop and maintain relationships with other professionals and have good collaborative skills. Students, HEIs and employers realise that IPE/IPL helps increase awareness of and challenge many aspects of a range of professional roles, including their own, and contributes to skill development for professional practice. Employers note transferability of the outcomes of IPE/IPL to professional practice.

What is not clear, however, is whether IPE/IPL programmes have progressed sufficiently in terms of focus and content. Social work education has historically retained a focus on the promotion of relationships and the clarification of role, purpose and identity (Trevillion and Bedford 2003 in Gillies et al. 2004). While learning methods have become more sophisticated demonstrating imagination, industry and ingenuity (Barr et al 2014) as evidenced by the range of IPE/IPL activity on offer, the content of IPE/IPL seems still to be largely focussed on the roles and skills of different professionals.

This research suggests that, although learning across a range of areas is gained, that the development of alternative knowledge bases requires greater attention. In addition, it appears that the more complex aspects of IPE/IPL (e.g. understanding limitations of each other's roles and responsibilities and addressing the responsibilities that fall between specific professional roles) requires a greater presence within IPE/IPL.

The outcome of this study suggests that IPE/IPL provision might be further developed to encourage a greater focus on the different knowledge sets required for professional practice and should address some of the more complex areas of skill sets in relation to inter-disciplinary practice. 
There are a number of challenges, however, to effective inter-professional learning present and future. Employers demonstrate concern relating to the impact of different professional priorities and hierarchies between professional groups within the workplace and in relation to the operation of different models for providing social care. Others suggested that finding ways to assist graduates to understand the pressures faced by different professionals and address poor communication between different professionals were the greatest challenges for NQSWs and for the development of relevant IPE/IPL activity.

Concerns of the marginalisation of the social work profession in practice, mirrored through IPE/IPL provision, might be responsible for our findings. It is widely recognised that different training and philosophical approaches have resulted in the separate and distinctive evolution of professional groups each with their own identity (Fitzsimmons and White 1997 in Chambers et al. 2013). Support for a move of identity and commitment from being focussed on the profession to being concerned with the organisation is required (Hafferty and Light 1995 in Chambers et al. 2013).

In an attempt to ensure that IPE/IPL programmes remain relevant to the workforce, HEls should liaise with employers and with newly qualified social workers to continue the discussion about the ways in which IPE/IPL activity has contributed to the preparation of graduates for practice and to identify areas for inclusion in IPE/IPL programmes.

Issues of professional confidence and an ongoing focus on identity in and between all professional groups within the context of collaborative practice continue to be identified as areas for further development. 
Although students and employers tended to view IPE/IPL positively only half of HEI staff who have a lead role in the planning and delivery of IPE/IPL believed that associated learning opportunities were positively received by students. In terms of the impact on professional practice just over half of students surveyed believed there had been a resulting change in their attitude towards working with other professionals and had gained learning from their IPE/IPL experience including improvement in team work and other collaborative working skills. Just under three quarters of the students surveyed felt better prepared as a direct result of IPE/IPL for professional practice in inter-disciplinary contexts.

It is important that the satisfaction with IPE/IPL activity in HEI s noted by participants of this study be acknowledged. It might be that although the external challenges for IPE/IPL provision are changing that the internal ones are not. HEI s are not without the imagination or the capability to devise creative and useful programmes of IPE/IPL. Organisational issues around the resourcing, planning and delivery constrain provision. IPE/IPL in practice learning appears to be sufficiently integrated and can perhaps be strengthened. Partnerships with employers are established but could possibly be developed further. One of the constraining factors might be around a collective understanding of what IPE/IPL is. To focus purely on IPE/IPL as learning between student groups from different professions runs the risk of relegating synergies to those that are easily available rather than those that bring the most learning. To harness the most useful synergies opens up greater possibilities in terms of the content and locus of the learning experience.

\section{References:}


Anderson, E. S. and Lennox, A. (2009) 'The Leicester Model of Inter-professional Education: Developing, delivering and learning from student voices for 10 years', J ournal of Inter-professional Care, 23 (6), pp. 557-573.

Barr, H. (1998) 'Competent to collaborate: towards a competency-based model for inter-professional education', J ournal of Inter-professional Care, 12 (2), pp. 181-187.

Barr, H., Helme, M. and D'Avray, L. (2011) 'Developing Inter-professional Education in health and social care courses in the United Kingdom, a progress report', Health Sciences and practice subject centre Higher Education Academy, occasional paper 12. Fareham: CAIPE.

Barr, H., Helme, M. and D'Avray, L. (2014) 'Review of Inter-professional Education in the United Kingdom 1997-2013', Fareham: CAIPE.

Barr, H. and Sharland, E. (2012) 'Inter-professional Education in Qualifying Social Work', in Lishman, J. (ed), Social Work Education and Training, 199-210. London, J essica Kingsley.

Barr, H.and Shaw, I. (1995) 'Shared Learning: Selected Examples From the Literature'. London: CAIPE.

Carpenter, J. (2011) 'Evaluating Social Work Education: A Review of Outcome, Measures, Research Design and Practicalities', Social Work Education, 30 (02), pp. 122-140.

Chambers, A., Clouder, L., Jones, M. and Wickham, J. (2013) 'Collaborative health and social care, and the role of Inter-professional education', in Porter, S.B. (ed), Tidy's Physiotherapy. $15^{\text {th }}$ edition. Edinburgh: Saunders Elseveir, pp. 23-29.

Foster, R. and Macleod Clark, J. (2015) 'Moderating the stereotypical views of health and social care students: the role of Inter-professional education', Journal of Inter-professional care, 29 (1), pp. 34-40.

Gillies, B., Simpson, M and Walker, L. (2004) 'Learning for Effective and Ethical Practice: Opportunities for Inter-professional Learning'. Dundee: Scottish Institute for Excellence in Social Work Education.

Hawthorn, J. and Wilson, P. (2009) 'Significant Case Review: Brandon Lee Muir' [online] Scottish Police Services Authority. Available from: http://www. fairplayforchildren.org/pdf/1265566147.pdf

Joseph, S., Diack, L., Garton, F and Haxton, J. (2015) 'Reflections on delivering inter-professional education in practice', J ournal of Practice Teaching and Learning, 13 (2-3), pp. 32-44. 
Kirkpatrick, D, L. (1967) 'Evaluation of Training' in R. L. Craig and L.R. Bittel, (eds). 'Training and Development Handbook'. New York: McGraw Hill.

Low, H. and Barr, H. (2008) 'Practice learning for Inter-professional

Collaboration perspectives from programmes leading to the Social Work Degree', Report to the Department of Health. Fareham: CAIPE.

Quinney, A., and Hafford-Letchfield, T. (2012). Interprofessional Social Work: Effective Collaborative approaches. London: Sage.

Sharland, E. and Taylor, L. (2007) 'Interprofessional education for qualifying social work'. London: Social Care Institute for Excellence.

Stevenson, K., Seenan, C., Morlan, G. and Smith, W. (2012) 'Preparing students to work effectively in Inter-professional health and social care teams', Quality in primary care, 20 (3), pp. 227-30. 